\section{Production of Compounds labelled with Carbon-14 from Carbon-14 Dioxide accelerated in an Electric Field}

IT is well known that hot radioactive carbon-14 and tritium atoms can be used to produce labelled organic compounds often with very high specific activity ${ }^{1}$. This convenient method requires nevertheless a high neutron flux, often yields a cumbersome mixture of labelled compounds and moreover radia. tion damage frequently produces undesired effects. For these reasons, I have devised a new method in order to avoid such difficulties.

The procedure developed to prepare labelled compounds is based on the acceleration of carbon-14 dioxide by submitting it to a voltage of $500 \mathrm{~V}$. Under such conditions, carbon-14 is able to react with organic compounds or radicals. In the apparatus illustrated in Fig. 1, the two steel electrodes are removable. A thin layer of the organic material to be treated (about 2-10 mgm.) is spread on the cathode. The two bulbs of the cell have ground-glass joints. The cell is connected to a vacuum line and evacuated for an hour to a pressure of $10^{-6} \mathrm{~mm}$. mercury. After carbon-14 dioxide has been admitted at a pressure of $0.5 \times 10^{-1} \mathrm{~mm}$. mercury, an applied voltage of $500 \mathrm{~V}$. produces a discharge of 100-150 ramp. The cell is then removed and the organic layer diluted in a suitable solvent. After carrier is added, the active sample is purified chemically until it has constant activity. Indeed, part of the activity of the sample is to be attributed to adsorbed carbon-14 dioxide and is consequently labile. After this radiochemical separation, measurements of the radioactivities isolated are carried out by means of a gas-flow counter. By this method, the following simple organic molecules of the aliphatic and aromatic series have been labelled : acetamide, citric acid, succinic acid, benzoic acid and benzoates.

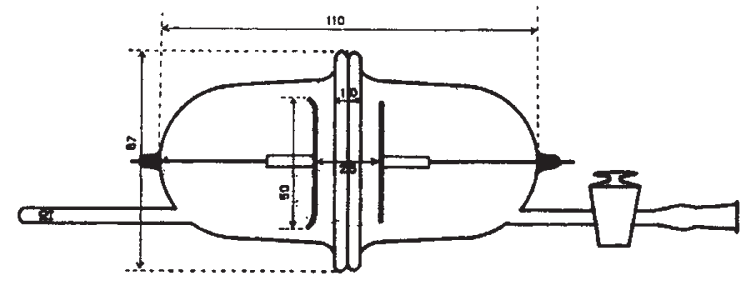

Fig. 1. Diagram of apparatus. Dimensions are in millimetrts

In most cases, specific activities are equal to about $0.2 \mathrm{mc}$./gm. This procedure considerably reduces interference by other adjacent labelled compounds. The specific activities obtained are variable, depend. ing on time of exposure, and increase with the latter. They are also a function of several other factors which are being examined in experiments now in progress. At the same time, the labelling mechanism will be studied. It is hoped that this new labelling technique will be applicable to other radionuclides.

I am indebted to Profs. G. Gueben and J. Govaerts, whose helpful suggestions and encouragement made this work possible. I acknowledge also grants from the Institut Interuniversitaire des Sciences Nucléaires of Belgium.

Institute of Nuclear Studies,

University of Liège. Sept. 30.

'Rowland, F. S., Turton, C. N., and Wolfgang, R., Science, 121, 715

(1955)..Rowland, F.S., and Wolfgang, R., Nucleonics, 14, 58 (1956).

\section{Hydrogen Overpotential on Germanium Electrodes}

EleCtron transfer reactions at the semiconductor electrolyte interface are of particular interest because it is not known experimentally whether the reaction kinetics depend upon the bulk electron concentration in the semiconductor. Results of recent measurements of the hydrogen evolution reaction on single crystal germanium electrodes are presented here. The electrode potential (versus the normal hydrogen electrode) was measured under suitable conditions of purity for analysis of the mechanism (Table 1).

Table 1. Hydroghe OVerpotential Data at Gremanium GlecTRODES $\left(28^{\circ} \mathrm{C}\right.$. AND $1 M$ HYDROCHLORIO ACID)

\begin{tabular}{|c|c|c|c|c|}
\hline $\begin{array}{l}\text { Crystal } \\
\text { surface } \\
\text { exposed }\end{array}$ & $\begin{array}{c}\text { Bulk } \\
\text { electron } \\
\text { concentra- } \\
\text { tion }\left(\mathrm{cm} .^{-3}\right)\end{array}$ & $\begin{array}{l}\text { Exchange cur- } \\
\text { rent (amp. cm.-2) }\end{array}$ & $-b(\mathrm{mV} .)^{*}$ & $\begin{array}{c}-\Delta \varphi_{i=0}=0 \\
(\mathrm{mV} .) \dagger\end{array}$ \\
\hline $\begin{array}{l}\text { Unknown } \\
\text { Unknown } \\
(100) \\
(100) \\
(110) \\
(111)\end{array}$ & $\begin{array}{l}4 \times 10^{14} \\
3 \times 10^{12} \\
\sim 10^{16} \\
\sim 10^{12} \\
\sim 10^{18} \\
\sim 10^{18}\end{array}$ & $\begin{array}{c}1.4 \times 10^{-8} \\
4.7 \times 10^{-6} \\
(2.2 \pm 0.3) \times 10^{-6} \\
(2.3 \pm 0.8) \times 10^{-1} \\
(1.0 \pm 0.2) \times 10^{-1} \\
(1 \cdot 9 \pm 0.4) \times 10^{-8}\end{array}$ & $\begin{array}{c}113 \\
102 \\
115 \pm 12 \\
109 \pm 5 \\
116 \pm 2 \\
148 \pm 9\end{array}$ & $\begin{array}{l}45 \\
1 \cdot 5 \\
29 \pm 10 \\
26 \pm 6 \cdot 6 \\
35 \pm 4 \\
41 \pm 20\end{array}$ \\
\hline
\end{tabular}

$\Delta \varphi_{1}=0$ is the rest potential of the electrode.

The case where care was taken to ensure that the crystallographic planes were the same on both $n$ and $p$-type germanium (third and fourth entries in Table 1) shows that variation in the bulk semiconductor electron concentration does not produce a corresponding variation in parameters of the hydrogen evolution reaction.

The fact that $\Delta \Phi_{i=0}$ is substantially above zero for most cases shown in Table 1 is interpreted as being due to the dissolution of germanium, that is, the germanium electrode is behaving as a polyelectrode'. Such polyelectrode behaviour makes it impossible to obtain the stoichiometric number, $\nu$, for the hydrogen evolution reaction from an analysis of the overpotential - current curve as $\gamma_{i}$ goes to zero ${ }^{2}$. However, for one electrode $\Delta \varphi_{i=0}$ is essentially zero and here an analysis of the $\eta$ versus $i$ curve gives $v=1 \cdot 06$.

Bockris (personal communication) has recently shown that a germanium electrode (supposedly the (110) crystal plane) is covered with a monolayer of adsorbed hydrogen atoms. When this fact is combined with the fact that the Tafel slope is $-2 R T / F$ and the stoichiometrie number is 1 , it can be shown that the only possible simple mechanism for the hydrogen discharge reaction from acid solution is ${ }^{2}$ :

$$
\begin{gathered}
\mathrm{H}_{3} \mathrm{O}++e^{-} \stackrel{\text { fast }}{\longrightarrow} \mathrm{GeH}+\mathrm{H}_{2} \mathrm{O} \\
\mathrm{H}_{3} \mathrm{O}++\mathrm{GeH}+e^{-} \stackrel{\text { slow }}{\longrightarrow} \mathrm{Ge}+\mathrm{H}_{2}+\mathrm{H}_{2} \mathrm{O}
\end{gathered}
$$

(Ge here indicates surface germanium atoms).

This presupposes the mechanism of the hydrogen evolution reaction to be the same on all the german. ium crystal surfaces and that the germanium electrode is behaving like a metallic electrode. A more detailed discussion of this work will appear elsewhere. V. R. ERdéLYI Mino Green

Zenith Radio Corporation

Chicago 39. Aug. 19.

1 Frumkin, Z. phys. Chem., 160, 116 (1932). Wagner and Traud, Electrochem. 44, 391 (1938) Bockris, "Modern Aspects Eilectrochemistry", 253 (Butterworths Sci." Pub., 1954). ${ }^{2}$ Bockris and Potter, J. Electrochem. Soc., 99, 169 (1952). 